\title{
O ÍNDICO - UM OCEANO DE MULTICULTURALIDADES, IMAGINAÇÃO LITERÁRIA E INSULARIDADES
}

\author{
Carmen Tindó Secco ${ }^{1}$
}

Resumo: A importância do oceano Índico e da Ilha de Moçambique para a poesia moçambicana. Fundamentada pelos Estudos Culturais, pelos estudos sobre a Nova História e a teoria da poesia, nossa leitura tenciona evidenciar que as multiculturalidades presentes no Índico e na Ilha de Moçambique fizeram desses espaços lugares inspiradores da imaginação literária e artística, paisagens privilegiadas de poemas de Luis Carlos Patraquim, Rui Knopfli, Eduardo White, Sangare Okapi, dentre outros poetas, bem como do filme A Ilha dos Espíritos, do cineasta Licínio Azevedo.

Palavras-chave: Oceano Índico; poesia; Moçambique.

Imaginem uma ilha... Uma pequena ilha, carregada de estórias e história. Perpassam por ela inúmeras rotas de transnacionalidade, marcas de muitas diferenças que fazem parte de diversos povos que construíram Moçambique, multifacetadas identidades que atravessam textos de grandes poetas - Virgílio de Lemos, Rui Knopfli, Luís Carlos Patraquim, Eduardo White, entre outros - e de cineastas, como Licínio Azevedo (2012, [s.p.]), autor do filme A Ilha dos Espíritos, que ressalta a importância econômica, política, histórica, cultural dessa ínsula, durante séculos:

Muito antes de dar nome ao país, a ilha de Moçambique teve um papel fundamental no Oceano Índico durante séculos. Ponto de paragem de caravelas, ponto de encontro de piratas, lugar de mistura de raças, ela ergue muralhas que encerram ruas tortuosas cheias de vida, pontuadas por casas

1 Professora Titular de Literaturas Africanas da Faculdade de Letras da Universidade Federal do Rio de Janeiro-UFRJ: carmen.tindo@gmail.com. 
O Índico - um oceano de ... - 148

senhoriais, casebres cobertos de macuti, igrejas, mesquitas, templos hindus, pequenos comércios...

Ilha de Moçambique, geografia fundadora, banhada por um oceano, que se institui como metáfora plural de configurações identitárias múltiplas: culturais, econômicas, religiosas, históricas, literárias, entre outras.

A Ilha de Moçambique e o Índico são caminhos de cruzamentos de culturas. A história - narração e transmissão de geração em geração, transformada em relatos de acontecimentos - se perpetua em registros e reflexões críticas acerca do passado e do presente insular. Ilha de Moçambique, mistura de vivências cotidianas de sua gente com memórias e espíritos dos antepassados.

Ponte sobre o Índico, sons, cores, histórias, $m$ 'siro ${ }^{2}$ no rosto das mulheres, neblinas - essas são algumas das imagens iniciais do documentário A Ilha dos Espíritos, de Licínio de Azevedo (ILHA, 2009). Barcos com gente simples, transportando cargas e pessoas. Portas árabes, através das quais penetraram culturas vindas do Oriente. Ilha pertencente à costa índica, que se estende até Sofala. Ilha habitada por povos swahili, que tinham estreito relacionamento com o comércio. Ilha de Moçambique, cheia de espíritos e religiosidades.

No filme de Licínio, o vento da Ilha ilumina e acaricia os rostos dos velhos, das crianças, das mulheres... Levanta a palha do macuti que cobre as casas de pedra do lado pobre da Ilha. A câmera focaliza o dia a dia dos ilhéus arrumando suas redes de pescar. O hibridismo presente se manifesta no paladar que degusta a xima branca com galinha e salada, nas religiosidades que se revelam em igrejas católicas e mesquitas, com seus sinos e minaretes. O artesanato em metal brilha ao sol. Espíritos do outrora saem das sombras, esvoaçantes, e percorrem ruas. A tela do documentário tenta captá-los mais concretamente, mas eles escapam e desaparecem das cenas, sem passarem pelas portas. São alegorias cinematográficas que buscam representar os espíritos da Ilha: o cotidiano, os costumes, as crenças e as religiões. Os tambores soam para saudar a vida

\footnotetext{
$2 \mathrm{O}$ m'siro ou mussiro é um produto de tratamento de beleza, usado pelas mulheres de origem macua (etnia africana) da Ilha de Moçambique. É uma pasta feita de raiz de árvore, completamente natural, sem aditivos artificiais. A raiz é moída numa pedra e misturada com água para formar um creme que suaviza e amacia a pele. Alega-se que seja rejuvenescedor e combate a acne. Por isso, as mulheres macuas, desde a adolescência, passam esse preparado em seus rostos.
} 
e os espíritos. Sons longínquos trazem rituais macuas ainda tão presentes. Evocam, também, a figura de Camões, que por ali passou, deixando, entre as memórias do lugar, o tom épico das aventuras marítimas portuguesas.

Ilha de multiculturalidades, desde o século XVIII, cheia de objetos europeus, africanos, asiáticos, comprovando origens diversas que se entrecruzaram naquele espaço. Espaço tenso, que revela lembranças tristes e dolorosas: do colonialismo, da escravidão que levou muitos africanos para as Américas e a Europa.

É preciso ter acuidade para perceber, sob a beleza da paisagem e das diversas multiculturalidades existentes, os jogos de poder ali exercidos através dos tempos. A reflexão de José Luís Cabaço denuncia a "falsa harmonia”, em geral, atribuída a essa Ilha:

\begin{abstract}
Uma harmonia e tolerância que têm sido lidas no secular cosmopolitismo da região, mas que se deve também procurar no, igualmente secular, exercício de resignada adaptação aos poderes, costumes e despotismos que se sucederam, impostos por gentes de paragens longínquas.

Será, provavelmente, de beleza, de harmonia e tolerância a primeira percepção do visitante. Porém, essa unidade emocional encerra duas realidades. São duas, com efeito, as cidades que compõem o aglomerado urbano a que se deu o nome de Moçambique. Sendo complementares, elas são, todavia, profundamente antagônicas. Contrapõem-se, ao longo da História da efetiva colonização portuguesa, no plano social, econômico, cultural, religioso, urbanístico. Representam duas realidades que coexistiram mais do que conviveram; duas realidades traçadas por destinos tendencialmente paralelos e em que os momentos de convergência foram episódicos e inconsequentes. Representam o verso e o anverso da complexa verdade desta fascinante Ilha.

O discurso oficial, por muitos anos, procurou veicular a imagem de que a Ilha de Moçambique representava uma síntese harmônica de influências culturais. Com isso, se reprimiu a herança que representava a cidade de macuti em benefício da história e do patrimônio monumental representado pela cidade de pedra e cal. Exaltou-se o seu orientalismo para se lhe retirar o localismo e pretendeu-se que essa herança mestiça se fundia na história da dominação ocidental, reduzindo-a à gesta dos "Descobrimentos". (CABAÇO, 2002, p. 82)
\end{abstract}

Ilha, metáfora e metonímia do Índico, em cujas águas tantos comércios e trocas se fizeram ao longo dos séculos. Ilha, banhada por um oceano literário que inspirou tantos poetas. Ana Mafalda Leite assim define essa ínsula:

Ilha, sinédoque também parcial do país, de uma vivência que revivo, entranhada dessa natural, cultural, multiplicidade, em que me conjugo por herança, pelo corpo e pelos sentidos e ainda pela memória do sonho e pela imaginação, ou seja, pela poesia. (LEITE, 2002, p. 103) 
Hoje, fundamentados teoricamente nos Estudos Culturais sobre o Índico, alguns estudiosos da literatura e da história moçambicana - José Luís Cabaço, Francisco Noa, Ana Mafalda Leite, Fátima Mendonça, Elena Brugioni, Rita Chaves, Paula Meneses, Nazir Can, Jéssica Falconi, entre os quais também nos incluímos -, deram maior visibilidade a esse oceano, chamando atenção para a antiga transnacionalidade índica:

o Oceano Índico já era no século XV um espaço transnacional, uma cultura mundial cosmopolita com um sistema econômico integrado, constituindo [...] trocas, peregrinações e um mundo de diversidade, culturas, conhecimentos. [...] Para um vasto número de comunidades, o Oceano Îndico significava uma oportunidade de viagem, intercâmbio e aprendizagem. (CUNHA, 2010, p. 12)

Questionando visões glorificadoras do Índico entendido como espaço cultural harmonioso, tais estudos discutem o hibridismo existente, há séculos, tanto econômica, política, social, como cultural e literariamente, ressaltando que há zonas de atritos e tensões. Francisco Noa (2012, p. 2) chama atenção:

O Oceano Índico possui, reconhecidamente, uma importância vital e multilateral para os países por ele banhados, incluindo Moçambique, a região da África Austral e Oriental, a Ásia e parte do Oriente Médio, podendo configurar-se como um novo paradigma transnacional no que concerne às relações culturais $[\ldots]$.

Lançando novo olhar sobre a história, os estudos culturais acerca do Oceano Î́ndico retiram da sombra "outras geografias do conhecimento" (CUNHA, 2010, p. 10), outras paisagens, outras histórias.

Observamos quealguns poetas moçambicanos já demonstravam uma perspectiva descentrada, uma mirada insubmissa em relação à história do Î́ndico, tendo em vista que suas produções líricas, ao celebrarem esse oceano como um espaço multicultural, ostentaram um caráter de rebeldia em relação aos paradigmas.

Apesar de o mar não ter sido metáfora recorrente nas literaturas africanas de língua portuguesa, há uma vertente da poesia moçambicana em que o Oceano Índico é representado não apenas tematicamente, mas enquanto elemento inspirador da própria produção lírica.

Francisco Noa (2012, p. 10) designou tal vertente de "poética da oceanidade", pois agrega uma série de poetas, cujas composições líricas apresentam "forte vocação marítima", como ocorre com Orlando Mendes, Rui Knopfli, Virgílio de Lemos, Glória de Sant’Anna, Luís Carlos 
Patraquim, Eduardo White, Nélson Saúte, Júlio Carrilho, Guita Júnior, Adelino Timóteo, Sangare Okapi, entre outros. Duas linhas poéticas demarcam as produções desses "poetas do mar Índico", reunindo-os segundo as direções que tomam suas respectivas produções líricas. Desse modo, nas águas índicas da poesia moçambicana, desenham-se dois eixos: um, em que o Índico é cartografado por um viés existencial, intimista, lírico, direcionado aos sonhos e afetos; outro, que apresenta uma dicção corrosiva e irônica em relação à história oficial.

Embora haja diferenças entre esses eixos, ambos ostentam forte erotismo, que propicia a associação do mar à escrita literária. O Índico, metáfora de rede de relações e afetos, espaço de descentradas viagens, de contraviagens, institui-se, "a contrapelo", como líquida e híbrida tapeçaria. Suas ilhas, metonimicamente, passam a representá-lo e são cantadas por diversos poetas.

Nélson Saúte (2006, p. 45), por exemplo, relaciona a mulher amada, musa inspiradora de sua poesia, à Ilha de Moçambique e esta à pátria moçambicana, herdeira de múltiplos legados culturais e históricos:

\footnotetext{
Vejo-te assim nos meus versos

tuas mãos africanas, indianas, árabes

tua comovente beleza

na cadência deste flamenco

nestas vozes ciganas tangendo-me

com as ocres cores de Sevilha

nos pátios da Ilha de Moçambique

onde tu bailas e voltas a bailar
}

Na linha dos afetos, também celebra intenso encantamento, expresso no azul de seus olhos, Virgílio de Lemos (1999b, p. 19), sempre enfeitiçado por Muhipíti, nome original da Ilha de Moçambique, cujas relações entre a amada e a terra moçambicana foram tema de muitos poetas e poemas, como em "Língua de fogos silabares", de 1959):

Nos teus bicos, teus lábios, teus brincos se insularizam meus dedos, meus gritos, sóis que penetram teu desejo, teus muros, tua fome de incendiados ventres e mares.

E na estatuária swahili de teu cio de ouro súbita e singular, és tu e não outra qualquer, quem por mim viaja, língua de fogos silabares. 
O Î́ndico - um oceano de ... - 152

Virgílio, desde 1944, já exibia obsessivo pendor marítimo. O oceano para ele era fonte de erotismo, lugar de memórias, hibridismos e infinita imaginação criadora. Seus poemas sempre expressaram um fazer literário cosmopolita, universal, perpassado por reflexões filosóficas e questionamentos sobre a vida. Virgílio, por conseguinte, faz parte da "poética da oceanidade" (NOA, 2012, p. 10), tendo fundado nesta o viés afetivo, intimista, existencial, metapoético.

Outras ilhas do Índico integram também o universo poético de Virgílio. Sobre elas o poeta tinha plena consciência, discorrendo acerca de seus metafóricos significados não só literários, como históricos e culturais:

As ilhas do norte de Moçambique representam a permanência, através dos séculos, dos múltiplos entrecruzamentos culturais existentes no tecido social moçambicano. Eu canto Muipíti, pois lá se encontram heranças manuelinas, mouras, macuas, swahilis. Da Ilha do Ibo, trago a memória dos encantos swahilis e macuas, a imponência das fortalezas lusas e das construções árabes [...] Em cada ilha ou território visitado através de minha errância pelo mundo, estão presentes os elípticos labirintos que nutrem minha poesia. (LEMOS, 2009a, p. 26)

O Índico é o oceano literário através do qual paixões, afetos, ritmos, musicalidades e diversas trocas são, cartograficamente, representadas por olhares diversos de poetas, pintores, cineastas, romancistas.

Eduardo White, seguindo as trilhas poéticas de Glória de Sant'Anna e Virgílio de Lemos, cujos poemas celebraram os afetos e as belezas das índicas águas do norte moçambicano, capta fragmentos da memória histórica da Ilha de Moçambique, apreendendo um "Índico de cheiro triste”, pois nele nem sempre os comércios e trocas foram harmoniosos:

Sou ao norte a minha Ilha, os sinais e as sedas que ali se trocaram [...] um curandeiro macua, uma mulher que dance uma Índia tão distante [...] Amo-te sem recusas e o meu amor é esta fortaleza, esta Ilha encantada, estas memórias sobre as paredes [...]. (WHITE, 1996, pp. 24-26)

Outro grande poeta moçambicano cantor do Índico foi Rui Knopfli. Como Virgílio de Lemos, sua poética apresenta uma dicção descentrada e cosmopolita. No entanto, a poesia de Knopfli e a de Virgílio são muito diferentes. Enquanto a deste se insere num viés erótico, perpassado pelos afetos, a daquele se impõe pelo caráter irônico e corrosivo em relação à história da Ilha, do Î́ndico e de Moçambique. Consciente de sua multifacetada identidade, no poema "Naturalidade", ele se concebe mais africano que europeu, embora não negue suas heranças ocidentais. 
Ser natural, para ele, é ser, simultaneamente, um ser na diferença, na alteridade. Por isso, declara trazer no sangue "uma amplidão de coordenadas geográficas" que o caracteriza como cidadão do mundo, ao mesmo tempo que carrega em si as cores locais “do mar Índico”.

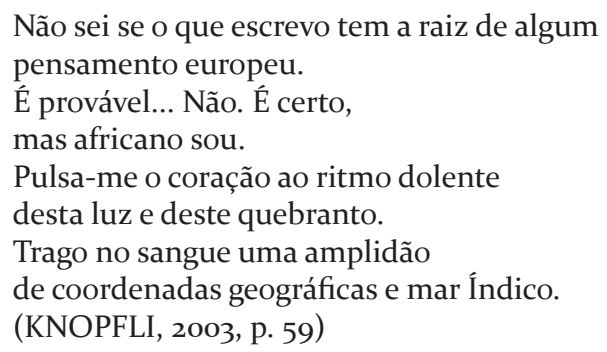

É por um prisma dissonante e plural múltiplo que o poeta representa a "Ilha de Moçambique", a "Ilha Dourada", cenário de diversos povos e culturas, cujos monumentos, construções arquitetônicas revelam uma história de intercâmbios, mas também de conflitos. Os versos de Knopfli contemplam a fortaleza lusa, a paisagem que traz à memória a convivência de barcos árabes e riquixás indianos, chineses. Apreendem religiosidades que se entrecruzam na Ilha, onde coexistem mesquitas, templos hindus, igrejas católicas e rituais macuas.

Por intermédio de uma perspectiva "a contrapelo" das ideologias dominantes, o sujeito lírico knopfliano aponta atritos, discriminações e opressões que perpassam o tecido histórico da Ilha de Moçambique, revelando que havia ali uma evidente cisão entre a cidade dos colonizadores e os bairros locais habitados por africanos. Rita Chaves (2002, p. 94), com base no historiador moçambicano António Sopa, adverte que, apesar de ter havido "uma insistência na harmonia como traço dominante entre os povos que aportaram na Ilha de Moçambique e os habitantes africanos de origem macua, as paisagens insulares exprimem desigualdades e assimetrias".

Segundo Ana Mafalda Leite (2006, p. 140), "Rui Knopfli convoca uma dimensão dramática para sua escrita, simultaneamente devedora de uma herança intertextual múltipla do Ocidente e de um enraizamento obtuso no telurismo local". Por essa ambiguidade, o Índico, na poesia dele, assume um sentido duplo: é um espaço crítico e corrosivo em relação ao passado histórico de Moçambique; é também um oceano literariamente cosmopolita, que permite à sua poesia diversas intertextualidades. 
O poeta Luís Carlos Patraquim também faz parte dessa vertente que envereda por um corrosivo repensar da história moçambicana, revisitando criticamente espaços matriciais da colonização, muitos dos quais se revelam impregnados tanto por memórias de tradições e ritmos africanos, como por traços ocidentais impostos pelos portugueses e por paladares árabes e indianos. Patraquim (1992, p. 42) aponta para essas misturas, deixando entrever, por suas interrogações, os atritos decorrentes da mesclagem das culturas ali presentes:

Minha ilha/vulva de fogo e pedra no Índico esquecida. Circum-navego-te, dos crespos cabelos da rocha ao ventre arfante e esculturo-te de azul e sol. Tu, solto colmo o oriente, para sempre de ti exilada.

Foste uma vez a sumptuosidade mercantil, cortesão impossível roçagando-se nas paredes altas dos palácios. Sobre a flor árabe e excisão esboçada com nomes de longe. São Paulo. Fadário quinhentista de "armas e varões assinalados". São Paulo e rastilho do evangelho nas bombardas dos galeões. São Paulo rosa, ébano, sangue, tinir de cristais, gibões e espadas, arfar de vozes nas alcovas efémeras. Nas ranhuras deste empedrado com torre a escandir lamentos dormirão os fantasmas? Almas minhas de panos e missangas gentis, quem vos partiu o parto em tijolo ficado e envelhecido?

Em clara intertextualidade com Camões, o sujeito poético põe sob suspeita a epopeia lusíada, rejeitando os padrões coloniais portugueses. Mergulha em paladares e sensualidades árabes que deixaram suas marcas no imaginário moçambicano, fazendo com que penetrem poeticamente em sua escrita, cujas heranças culturais reúnem traços orientais, ocidentais e africanos.

Em poetas de gerações mais recentes, encontramos também a Ilha de Moçambique e o Índico associados. Como os poetas mais velhos, os jovens poetas, entre os quais, Guita Jr., Adelino Timóteo, Sangare Okapi, seguem as duas vertentes estéticas já referidas em relação à oceanidade: a que acentua uma corrosividade do olhar em relação à história e a que persegue um viés existencial e afetivo.

Guita Júnior (2007, p. 71), em Os aromas essenciais, denuncia “[...] o medo - sombra negra - [que] assombra o presente". Sua "lira quebrada", partilhando a vertente corrosiva fundada por Knopfli e seguida por poetas como Patraquim e Nélson Saúte, acusa o desencanto decorrente da perda dos sonhos de liberdade.

Sangare Okapi e Adelino Timóteo, assumindo o legado deixado por Virgílio de Lemos e Eduardo White, optam por reatualizar, lírica e afetivamente, a Ilha de Moçambique, espaço matricial de inspiração 
literária de poetas anteriores. Adelino canta essa ínsula mítica, perpassada por traços culturais do Oriente e do Ocidente, comparando-a à Grécia mitológica, onde nasceu a poesia ocidental. Contudo, abraçando uma perspectiva poética cosmopolita, celebra poetas do Ocidente e do Oriente: Camões, Campos de Oliveira, Alberto de Lacerda, Patraquim, White Sophia de Mello Breyner, Eugénio de Andrade, Tagore (TIMÓTEO, 2002, p. 62 e 74).

Okapi é outra dessas novas vozes poéticas moçambicanas que rendem homenagem a poetas mais velhos. Em seus poemas, ele incorpora e ressignifica heranças do passado lírico moçambicano. Os sujeitos poéticos de seus versos, a par do desencanto e da angústia frente ao presente distópico, empreendem uma trajetória literária e visceral pelo âmago do Índico e da Ilha. É um percurso erótico em busca de uma identidade literária. Do outrora, emergem vozes poéticas do Índico e da Ilha de Moçambique: Campos de Oliveira, Knopfli, Virgílio de Lemos, Heliodoro Baptista, Guita Jr., Gulamo Khan, Eduardo White. No poema "Patraquimmiana", Patraquim e José Craveirinha são homenageados: "Sim, agora que o medo já não puxa lustro na cidade. Velho Zé,/ Livre e limpo da morte, regressas pelos carris da memória” (OKAPI, 2007, p. 39).

Observa-se, portanto, por parte dos poetas mais jovens, um culto às figuras tutelares da poesia moçambicana que celebraram o Índico e a Ilha de Moçambique. Ilha de fios múltiplos, de muitas histórias e estórias. Ilha, situada em índicas águas, povoada por sonhos e realidades. Ilha, que ata pontes entre tradições e modernidades, entre lugares de partilha, de emoções e enfrentamentos.

\title{
THE INDIAN - AN OCEAN OF MULTICULTURALITIES, LITE- RARY IMAGINATION AND INSULARITIES
}

\begin{abstract}
The importance of the Indian Ocean and the Island of Mozambique for Mozambican poetry. Based on Cultural Studies, New History and Poetry, our reading intends to show that the multiculturalities present in the Indian Ocean and on the Island of Mozambique made these spaces inspiring places of literary and artistic imagination, privileged landscapes of poems by Luis Carlos Patraquim, Rui Knopfli, Eduardo White, Sangare Okapi, among other poets, as well as the film A Ilha dos Espíritos, by Licínio Azevedo.
\end{abstract}

Keywords: Indian Ocean; poetry; Mozambique. 
O Índico - um oceano de ... - 156

\section{REFERÊNCIAS}

ABDALA JR., Benjamin. De voos e ilhas. Literatura e comunitarismos. São Paulo: Ateliê, 2003.

ALMEIDA, Cíntia Machado de Campos. Na ponta da pena: Moçambique em letras e cores. Dissertação (mestrado em Literaturas Africanas de Língua Portuguesa) Universidade Federal do Rio de Janeiro. Rio de Janeiro, 2006.

ALMEIDA, Cíntia Machado de Campos. Viagens de fora para dentro: profanações e vagamundagens de Luís Carlos Patraquim. Tese (doutorado em Literaturas Africanas de Língua Portuguesa) - Universidade Federal do Rio de Janeiro. Rio de Janeiro, 2014.

ANGIUS, Fernanda. Entre os oceanos e o amor viaja o poeta. In: LEMOS, Virgílio de. Eroticus moçambicanus: breve antologia da poesia escrita em Moçambique (1944/1963). Rio de Janeiro: Nova Fronteira / UFRJ, 1999, pp. 131-138.

AZEVEDO, Licínio. Sinopse do filme A Ilha dos Espíritos (2007). In: FESTIM - Festival de Cinema Itinerante de Língua Portuguesa, de 9 a 16 de maio de 2012, Lisboa. Disponível em: <https://festin-festival.com/festin-2012/programacao/competicaolonga-metragem-2012>. Acesso em: 6 maio 2018.

BOSI, Alfredo. O ser e o tempo da poesia. São Paulo: Companhia da Letras, 2000.

BRUGIONI, Elena. Narrando o(s) Índico(s). Reflexões em torno das "geografias transnacionais do imaginário". Dossier "Narrando o Índico". Revista Diacrítica Literatura, Braga (Húmus Edições-CEHUM), v. 27, n. 3, 2013, pp. 121-136. Disponível em: <http://www.academia.edu/6233039/Dossier_Narrando_o_Oceano_Indico>. Acesso em: 2 jan. 2015.

CABAÇO, José Luís. Moçambique: identidade, colonialismo e libertação. São Paulo: Editora Unesp / ANPOCS, 2009.

CABAÇO, José Luís. Uma ilha cheia de histórias. Metamorfoses - Revista da Cátedra Jorge de Sena da Faculdade de Letras da UFRJ, Rio de Janeiro, v. 1, n. 3, 2002, pp. 76-84.

CABRITA, António. Posfácio. In: LEMOS, Virgílio de. A invenção das ilhas. Antologia. Maputo: Editora da Escola Portuguesa de Maputo, 2009.

CAN, Nazir. Índico e(m) Moçambique: notas sobre o outro. Dossier "Narrando o Índico", Revista Diacrítica - Literatura, Braga (Húmus Edições-CEHUM), v. 27, n. 3, 2013, pp. 93-120. Disponível em: <http://ceh.ilch.uminho.pt/publicacoes/Diacritica_27-3. pdf>. Acesso em: 21 dez. 2014.

CHAVES, Rita. A ilha de Moçambique: entre as palavras e o silêncio. Metamorfoses Revista da Cátedra Jorge de Sena da Faculdade de Letras da UFRJ, Rio de Janeiro, v. 1, n. 3, 2002, pp. 93-101. 
CHAVES, Rita. Angola e Moçambique - experiência colonial e territórios literários. São Paulo: Ateliê, 2005.

CHAVES, Rita; MACEDO, Tania. Passagens para o Índico. Encontros brasileiros com a literatura moçambicana. Maputo: Marimbique, 2012.

COLLOT, Michel. Do horizonte da paisagem ao horizonte dos poetas. In: ALVES, Ida Ferreira; FEITOSA, Márcia Manir Miguel (Orgs.). Literatura e paisagem: perspectivas e diálogos. Niterói: Editora da UFF, 2010, pp. 191-217.

CORRÊA, Roberto Lobato; ROSENDAHL, Zeny. Paisagem, tempo e cultura. 2. ed. Rio de Janeiro: EdUERJ, 2004.

CUNHA, Teresa. Para além de um Índico de desesperos e revoltas. Tese de Doutorado em Sociologia. Coimbra, Universidade de Coimbra, 2010.

FALCONI, Jessica. Utopia e conflittualità. Ilha de Moçambique nella poesia mozambicana contemporanea. Roma: Aracne, 2008.

FALCONI, Jessica. "Para fazer um mar". Literatura Moçambicana e Oceano Índico. Dossier "Narrando o Índico". Revista Diacrítica - Literatura, Braga (Húmus EdiçõesCEHUM), v. 27, n. 3, 2013, pp. 77-92. Disponível em: <http://www.academia. edu/8987493/Para_fazer_um_mar._Literatura_mocambicana_e_Oceano_Indico>. Acesso em: 28 dez. 2014.

GONÇALVES, Guilherme de Sousa Bezerra. Para inventar um balé marinho: Glória de Sant’Anna. Dissertação (Mestrado em Literaturas Africanas de Língua Portuguesa) Universidade Federal do Rio de Janeiro. Rio de Janeiro, 2013.

GUITA JR. Os aromas essenciais. Lisboa: Caminho, 2007.

ILHA DOS Espíritos, A. Direção de Licínio Azevedo. Moçambique, Ébano Multimédia e Technoserve, 2009. Documentário (63 minutos). DVD.

KNOPFLI, Rui. Antologia poética. Lisboa: Imprensa Nacional-Casa da Moeda, 2003.

LABAN, Michel. Moçambique: encontro com escritores. 3 vols. Porto: Fund. Eng. António de Almeida, 1998. LEITE, Ana Mafalda. Kheniriwa: “omaka ti wowi” oyaka weiwo: não se pergunta para que lado é o mar quando se caminha na sua direcção. Metamorfoses 3 - Revista da Cátedra Jorge de Sena para Estudos Literários Luso-Afro-Brasileiros da F. Letras da UFRJ. Lisboa/Rio: Caminho/UFRJ, 2002, pp. 103-108.

LEITE, Ana Mafalda. Literaturas africanas e formulações pós-coloniais. Lisboa: Colibri, 2003 .

LEITE, Ana Mafalda. Poesia moçambicana: ecletismo de tendências. Poesia Sempre, Rio de Janeiro, ano 13, n. 23, 2006, pp. 139-142.

LEITE, Ana Mafalda et al. (Orgs.). Nacão e narrativa pós-colonial - I. Lisboa: Colibri, 2013. 
O Î́ndico - um oceano de ... - 158

LEMOS, Virgílio de. Eroticus mozambicanus. In: Panorama do Congresso Internacional sobre as Novas Literaturas Africanas de Língua Portuguesa. Lisboa (10 a 14 dez. 1997): Comissão para as Comemorações dos Descobrimentos Portugueses, 1997, pp. 124150 .

LEMOS, Virgílio de. Eroticus moçambicanus. Antologia poética. Organização e apresentação de Carmen Tindó Secco. Rio de Janeiro: Nova Fronteira Fac. Letras da UFRJ, 1999a.

LEMOS, Virgílio de. Ilha de Moçambique. A língua é o exílio do que sonhas. Maputo: AMOLP, 1999b.

LEMOS, Virgílio de. A invenção das ilhas. Antologia. Org. de António Cabrita. Maputo: Editora da Escola Portuguesa de Maputo, 2009a.

LEMOS, Virgílio de. Jogos de prazer. Virgílio de Lemos E Heterônimos: Bruno dos Reis, Duarte Galvão e Lee-Li Yang. Org. Ana Mafalda Leite. Lisboa: Imprensa Nacional Casa da Moeda, 2009b.

LEMOS, Virgílio de. A dimensão do desejo. Maputo: Amolp, 2012.

LOBATO, Alexandre. Ilha de Moçambique: notícia histórica. In: SOPA, António; SAÚTE, Nélson (Orgs.). A Ilha de Moçambique pela voz dos poetas. Lisboa: Edições 70, 1992, pp.169-182.

MENDONÇA, Fátima. Poetas do Índico - 35 anos de escrita. Mulemba. Revista do Setor de Literaturas Africanas da UFRJ, Rio de Janeiro, v. 1, n. 4, jan.-jul. 2011, pp. 16-37. Disponível em: <http://setorlitafrica.letras.ufrj.br/mulemba/download/artigo_4_2. pdf>. Acesso em: 26 dez. 2014.

MORAES, Viviane Mendes de. Canto em lira quebrada: uma leitura da poética de Guita Jr. Dissertação (Mestrado em Literaturas Africanas de Língua Portuguesa) - Universidade Federal do Rio de Janeiro. Rio de Janeiro, 2010.

NOA, Francisco. Literatura moçambicana: memória e conflito, itinerário poético de Rui Knopfli. Maputo: Universidade Eduardo Mondlane, 1997.

NOA, Francisco. O Oceano Índico e as rotas da transnacionalidade na literatura moçambicana. Publicação do Centro de Estudos Sociais Aquino de Bragança, Cesab, 2012. Disponível em: <http://cesab.edu.mz/wpcontent/uploads/2012/10/ OceanoIndicoTransnacionalidaPoesiaMocambicana-2012.pdf>. Acesso em: 13 dez. 2014.

NOA, Francisco. Os poetas levarão pelo Índico a poesia moçambicana. [Entrevista]. Literatas 50. Revista de Literatura Moçambicana e Lusófona, Ano II, n. 50, 18 jan. 2013, pp. 8-14. Disponível em: <http://macua.blogs.com/files/literatas-5o.pdf>. Acesso em: 16 dez. 2014. 
OKAPI, Sangare. Mesmos barcos ou poemas da revisitação do corpo. Maputo: AEMO, 2007.

PATRAQUIM, Luis Carlos. Monção. Maputo: INLD, 1980.

PATRAQUIM, Luis Carlos. A inadiável viagem. Maputo: AEMO - Associação dos Escritores Moçambicanos, 1985.

PATRAQUIM, Luis Carlos. Vinte e tal novas formulações e uma elegia carnívora. Lisboa: ALAC, 1992.

PATRAQUIM, Luis Carlos. Antologia poética. Org. Carmen Tindó Secco. Belo Horizonte: Ed. UFMG, 2011.

PAZ, Octavio. O arco e a lira. Trad. Olga Savary. Rio de Janeiro: Editora Nova Fronteira, 1982.

PAZ, Octavio. A dupla chama: amor e erotismo. Trad. Wladyr Dupont. São Paulo: Siciliano, 1994 .

RIBEIRO, Margarida Calafate; MENESES, Maria Paula (Orgs.). Moçambique: das palavras escritas. Santa Maria da Feira: Afrontamento, 2008.

ROCHA, Aurélio. Moçambique: história e cultura. Maputo: Texto, 2006.

SAÚTE, Nélson. A pátria dividida. Lisboa: Veja, 1992.

SAÚTE, Nélson. Os habitantes da memória. [Entrevistas com escritores moçambicanos]. Praia-Mindelo: Centro Cultural Português, 1998.

SAÚTE, Nélson. A viagem profana. Maputo: Marimbique, 2003.

SAÚTE, Nélson. Maputo blues. Maputo: Ndjira, 2006.

SAÚTE, Nélson. Livro do Norte e outros poemas. Maputo: Marimbique, 2012.

SAÚTE, Nélson; MENDONÇA, Fátima. Antologia da nova poesia moçambicana. Maputo: AEMO, 1993.

SECCO, Carmen Lucia Tindó (Org.). O mar nas letras moçambicanas. In: Antologia do mar na poesia africana do século XX. V. 3: Moçambique, Guiné-Bissau, São Tomé e Príncipe. Rio de Janeiro: UFRJ/Coordenação dos Cursos de Pós-Graduação em Letras Vernáculas e Setor de Literaturas Africanas em Língua Portuguesa, 1999, pp. 48-57.

SECCO, Carmen Lucia Tindó. A magia das letras africanas: ensaios escolhidos sobre as literaturas de Angola, Moçambique e alguns outros diálogos. Rio de Janeiro: ABE Graph/Barroso Produções Editoriais, 2003. (2. ed. rev.: Rio de Janeiro: Quartet, 2008). 
O Índico - um oceano de ... - 160

SECCO, Carmen Lucia Tindó. A vertigem da criação. In: A magia das letras africanas: ensaios escolhidos sobre as literaturas de Angola e Moçambique e alguns outros diálogos. Rio de Janeiro: ABE Graph Editora/Barroso Produções Editoriais, 2003, pp. 141-149.

SECCO, Carmen Lucia Tindó. Entre sonhos e memórias: trilhas da poesia moçambicana. Poesia sempre, Rio de Janeiro (Fundação Biblioteca Nacional), v. 23, 2006, pp. 229249.

SECCO, Carmen Lucia Tindó. Índicos cantares: o imaginário da Ilha de Moçambique pelas vozes dos poetas. In: GARCIA, Mar; HAND, Felicity; CAN, Nazir (Orgs.). Indicities/ indices/indícios: hybridations problématiques dans les littératures de l'Océan Indien. Paris: Editions K’a, 2010, pp. 165-176.

SOPA, António; SAÚTE, Nélson (Orgs.). A ilha de Moçambique pela voz dos poetas. Lisboa: Edições 70, 1992.

SPINUZZA, Giulia. A poética de Eduardo White. Dissertação (Mestrado em Literaturas Africanas de Língua Portuguesa) - Universidade de Lisboa. Lisboa, 2009.

TIMÓTEO, Adelino. Viagem à Grécia através da Ilha de Moçambique. Maputo: Ndjira, 2002.

WHITE, Eduardo. Amar sobre o Índico. Maputo: AEMO, 1984.

WHITE, Eduardo. O país de mim. Maputo: AEMO, 1989.

WHITE, Eduardo. Os materiais do amor, seguido de O desafio à tristeza. Lisboa: Caminho, 1996.

WHITE, Eduardo. Janela para Oriente. Lisboa: Caminho, 1998.

WHITE, Eduardo. Dormir com Deus e um navio na língua. Braga: Labirinto, 2001. 